\title{
Evaluation of Antioxidant and Antimicrobial Properties of the Angolan Cymbopogon Citratus Essential Oil With a View to Its Utilization as Food Biopreservative
}

\author{
Marta O. Soares ${ }^{1,2}$, Ana F. Vinha ${ }^{2,3}$, Sérgio V. P. Barreira ${ }^{3}$, Filipe Coutinho ${ }^{1}$, Sérgio Aires-Gonçalves ${ }^{3,4}$, \\ Maria B. P. P. Oliveira ${ }^{2}$, Pedro C. Pires ${ }^{1,5} \&$ Ana Castro $^{3}$ \\ ${ }^{1}$ CITS/Centro de Investigação em Tecnologias da Saúde, R. José António Vidal, 67, 4760-012, Vila Nova de \\ Famalicão, Portugal \\ ${ }^{2}$ REQUIMTE/Dep. Ciências Químicas, Faculdade de Farmácia, Universidade do Porto, Rua Jorge Viterbo \\ Ferreira, Porto, Portugal \\ ${ }^{3}$ FCS/UFP/Faculdade Ciências da Saúde, Universidade Fernando Pessoa, R. Carlos da Maia, 296, 4200-150, \\ Porto, Portugal \\ ${ }^{4}$ ARS/Norte, ACES-Maia/Valongo, Centro de Saúde de Ermesinde, Rua da Bela, Ermesinde, Portugal \\ ${ }^{5}$ Instituto Superior Politécnico de Benguela, Av. Governador Moutinho t-125, Benguela, Angola \\ Correspondence: Ana F. Vinha, Faculdade de Ciências da Saúde, Universidade Fernando Pessoa. Rua Carlos da \\ Maia, n.296, 4200-150 Porto, Portugal. Tel: 351-22-507-4630. E-mail: acvinha@ufp.edu.pt, \\ anafvinha@gmail.com
}

Received: April 7, 2013 Accepted: May 2, 2013 Online Published: June 15, 2013

doi:10.5539/jas.v5n7p36 URL: http://dx.doi.org/10.5539/jas.v5n7p36

\begin{abstract}
It was studied the chemical composition, antioxidant, antibacterial and antifungal properties of the essential oil obtained from the Cymbopogon citratus of Angolan origin. Its major constituents analyzed by GC-MS were $\alpha$-citral (40.55\%), $\beta$-citral (28.26\%), myrcene (10.50\%) and geraniol $(3.37 \%)$. The essential oil antioxidant capacity was statistically identical to that of synthetic antioxidants (DPPH IC I0 $_{0}$ of $41.7 \mu \mathrm{g} / \mathrm{ml}$ ) and superior to that of extracts obtained from fresh leaves of the plant (DPPH IC ${ }_{50}$ of $55.7 \mu \mathrm{g} / \mathrm{ml}$ ). The oil also demonstrated to possess high antibacterial activity even against multidrug resistant strains of Staphylococcus aureus, Staphylococcus epidermidis, Escherichia coli and Klebsiella pneumoniae and antifungal activity against Candida albicans and Non-Candida albicans, Candida parapsilosis and Candida tropicalis. The results of this study, in conjunction with already published data on the properties of other Cymbopogon citratus oils, provide evidence that it could have a potential application as food preservative.
\end{abstract}

Keywords: Cymbopogon citratus, essential oil, antioxidant, antibacterial, antifungal, biopreservative food

\section{Abbreviations}

AMC/AUG, amoxicillin/clavulamic acid; ATCC, American Type Culture Collection; BHT, butyl hydroxyl toluene; DMSO, dimethyl sulphoxide; DPPH, 2,2'-diphenyl-1-picrylhydrazyl; EO, essential oil; GC-MS, gas chromatography-mass spectrometry; HPLC, high performance liquid chromatography; $\mathrm{IC}_{50}$, half maximal inhibitory concentration; MET, methicillin; NCAC, non-Candida albicans Candida; P, penicillin G; VA, vancomycin.

\section{Introduction}

The use of essential oils (EOs) as additives in order to simultaneously tackle two issues related with food preservation, oxidation and microbial contamination, is an approach that gained adherents in recent years. This resulted from the realization that these natural products appeared to bring together the desired characteristics for that purpose, including, atoxicity at low concentrations, antioxidant activity, i.e. the ability to inhibit the process of food oxidation, antimicrobial properties and biodegradability. Hence it is not surprising the active research that is being conducted on the subject in order to uncover the properties of the thousands of EOs available (Lang \& Buchbauer, 2012). Obviously, the higher the antioxidant activity demonstrated and the greater the spectrum of activity of the EO, the better will be its performance as preservative. It is also desirable that the addition of oil does 
not change the organoleptic characteristics of the food. Interesting results have already been reported with EOs from various plants (Hyldgaard et al., 2012; Sessou et al., 2012). This paper describes the research done on the EO of Cymbopogon citratus (lemongrass) of Angolan origin. The EO of C. citratus is already in use by the pharmaceutical industry as a source of new phytochemical molecules for the development of new drugs. Previous studies on the leaf EO of C. citratus revealed, antityrosinase and antioxidant activities in human cells (Saeio et al., 2011), anti-inflammatory in rats (Gebnou et al., 2013), anti-carcinogenic effects and cholesterol reduction in mice (Costa et al., 2011; Bidinotto et al., 2012). Furthermore, many studies have reported the antimicrobial activity of lemongrass oil originating from different parts of the globe against a diverse range of microorganisms comprising Gram positive and Gram negative bacteria, yeast and fungi namely Bacillus cereus, Bacillus subtilis, Escherichia coli, Klebsiella pneumoniae (Naik et al., 2010), Salmonella choleraesuis, Pseudomonas aeruginosa, Staphylococcus aureus (Falcão et al., 2012) and Aspergillus flavus, Aspergillus fumigatus, Aspergillus niger, Alternaria alternata, Penicillium citrinum, Curvularia lunata and Trichoderma harzianum (Mahanta et al., 2007). In the work referred to in this article the objective was to evaluate the antimicrobial activity of the cymbopogon citratus on multidrug resistant strains of Staphylococcus (aureus and epidermidis) Escherichia coli, Klebsiella pnemoniae and fungi (Candida albicans, tropicalis and parapsilosis). All these microorganisms may be food-borne and by this route represent a severe public health problem in large scale (Easa, 2010). Food-borne diseases caused by bacteria and yeast are of major concern worldwide even in developed countries were up to $30 \%$ of the population have been reported to suffer from them every year. The severity of the problem might become more pronounced due to the proliferation of antibiotic-resistant strains (McAdam et al., 2012). Among the predominant bacteria involved in food-borne diseases, Staphylococcus aureus is a leading cause of gastroenteritis resulting from the consumption of a food in which enterotoxigenic staphylococci have grown and produced toxins. These are considered a potential biological threat because of their stability at high temperatures $\left(100^{\circ} \mathrm{C}\right.$ for $\left.1 \mathrm{~h}\right)$. While not regarded as highly lethal agents due to the low mortality associated with the illness, staphylococcal enterotoxins can incapacitate individuals for two weeks (Schelin et al., 2011). Moreover it is predictable that $S$. aureus will continue to develop new virulence characteristics and new patterns of synthetic antibiotic resistance (Fry et al., 2013). A similar drug resistance phenomenon is supposedly occurring with $S$. epidermidis (Widerström et al., 2012). E. coli is reported to cause bloody diarrhea and can sometimes cause kidney failure and even death. K. pneumoniae is second only to E. coli as a urinary tract pathogen and cases of enteroinvasive Klebsiella pneumoniae and Escherichia coli sepsis from contaminated hamburgers are documented (Sabota et al., 1998; Kim et al., 2005). As in the case of bacteria previously mentioned, Klebsiella infections are encountered far more often now than in the past probably due to the emergence of increasingly resistant strains (Saha et al., 2008). Apart from bacteria, fungal contamination of food is practically inevitable. Candida as many other yeasts and molds is undesirable in many foods manly due to its food spoiling activity, nevertheless, dangerous levels of candida have been found in yoghurt (Montagna et al., 1998). Candida spp. is responsible for the most prevalent opportunistic fungal infections in humans and of particular significance in immunocompromised individuals (Muñoz et al., 2006; Rodloff et al., 2011).

Additionally, and as this is an important characteristic for a food preservative, the antioxidant capacity of the Angolan Cymbopogon citratus EO was evaluated and compared with that of synthetic antioxidants. The use of natural substances to replace the synthetic antioxidants in food industry can result in important health benefits, since the latter have been associated with genotoxic and carcinogenic effects (Kahl et al., 1993, Ndhlala et al., 2010).

\section{Material and Methods}

\subsection{Plant Source}

The fresh aerial parts of $C$. citratus were obtained from a local market in Benguela, (latitude $12^{\circ} 58^{\prime}$ south; longitude $13^{\circ} 408^{\prime}$ east), Angola. The plants were identified by a taxonomist (Dr. Pedro Catarino Pires, ISPB, Benguela) and deposited in the Instituto Superior of Saúde de Benguela, ISPB, Benguela. The fresh plant sample was submitted to distillation $(4 \mathrm{~h})$ using a Clevenger apparatus to obtain the EO for further analysis. The procedure followed was that described in the European Pharmacopoeia (2011). The yield in EO was of 1.3\%, corresponding, on average, to $1.5 \pm 0.4 \mathrm{ml}$ of EO per $111 \mathrm{~g}$ of fresh plant sample. A total of six samples of fresh plant, purchased in different days were used to obtain the six samples of EO.

\subsection{Isolation, Characterization and Identification of Constituents}

The EO was analyzed by GC-MS carried out in a Hewlett-Packard 6890 gas chromatograph fitted with a HP1 fused silica column, interfaced with an Hewlett-Packard mass selective detector 5973 (Agilent Technologies) operated by HP Enhanced Chem-Station software, version A.03.00. Components were identified by their retention 
indices on both SPB-1 and SupelcoWax-10 columns and from their mass spectra. Retention indices, calculated by linear interpolation relative to retention times of $\mathrm{C} 8-\mathrm{C} 23$ of n-alkanes, were compared with those of authentic standards included in our own laboratory database.

\subsection{Total Phenolic Contents}

The amount of total phenolic compounds was determined in the aerial parts of $C$. citratus according to Jang et al. (2007) using the Folin-Ciocalteu reagent. Each sample was extracted using methanol, for one hour. In brief, $2.5 \mathrm{~g}$ of a dried leaves sample was added to $100 \mathrm{ml}$ of the solvent, under constant agitation for 1 hour. Afterwards, the solid was separated from the extract through vacuum filtration and a volume of $0.5 \mathrm{ml}$ of each extract was added to $0.5 \mathrm{ml}$ of Folin-Ciocalteu reagent. The mixture was left to rest for $3 \mathrm{~min}$ at room temperature before $1.0 \mathrm{ml}$ of sodium carbonate $6 \%$ was added to it. After standing at room temperature for $120 \mathrm{~min}$, absorbance readings were performed at $720 \mathrm{~nm}$ using a UV-Vis spectrophotometer (Beckman DU-64 spectrophotometer, Beckman Instruments Inc., Fullerton, CA). Total phenolics were quantified by means of a calibration curve obtained from measuring the absorbance of gallic acid standards. Results were expressed as milligrams of gallic acid equivalents per $100 \mathrm{~g}$ of fresh sample weight.

\subsection{Antioxidant Activity}

The antioxidant activity of C. citratus EO was evaluated by measuring the bleaching of the purple-colored ethanolic solution of 2,2-diphenyl-1-picrylhydrazyl free radical $\left(\mathrm{DPPH}^{\circ}\right)$. This methodology was performed using an ELX80 Microplate Reader (Bio-Tek) in the following way: the reaction mixture in each one of the 96-wells consisted of one of the different concentration of EO $(20 \mu \mathrm{L})$ and $280 \mu \mathrm{L}$ methanolic solution of DPPH radical $(0.5 \mathrm{mM})$. After 30 minutes incubation, the changes in color (from deep-violet to light-yellow) were measured at $517 \mathrm{~nm}$ (Shimadzu, model UV-1800), according to the method previously reported (Brand-Williams et al., 1995). The butyl hydroxyl toluene (BHT) was used as a positive control while ethanol was the negative one. The percentage of inhibition ( $I \%$ ) of DPPH radical was computed through the equation:

$$
I \%=\frac{A_{D P P H}-A_{s}}{A_{D P P H}} \times 100
$$

where, $A_{s}$ represents the absorbance of the solution of the sample extracts containing $\mathrm{DPPH}^{\bullet}$, and $A_{D P P H}$ is the absorbance of the $\mathrm{DPPH}^{\bullet}$ solution. All determinations were performed in triplicate. The concentration of extract sample required for $50 \%$ inhibition of the DPPH free radical $\left(\mathrm{IC}_{50}\right)$ was also calculated.

\subsection{Antibacterial Activity}

\subsubsection{Microorganisms}

The tested microorganisms used in this study were obtained from the Culture Collections of the Centro de Investigação em Tecnologias da Saúde (CITS). The antimicrobial activity of $C$. citratus $\mathrm{EO}$ was evaluated using the following laboratory control strains: Staphylococcus aureus (ATCC 25923), Staphylococcus epidermidis (ATCC 12228), Escherichia coli (ATCC 25922), Klebsiella pneumoniae (ATCC 13883), Candida albicans (ATCC 10231), Candida parapsilosis (ATCC 2219) and Candida tropicalis (ATCC 750) and the antibiotic

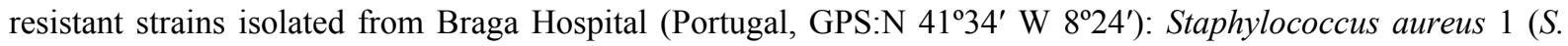
aureus 1); Staphylococcus aureus 2 (S. aureus 2); Staphylococcus epidermidis 1 (S. epidermis 1); Staphylococcus epidermidis 2 (S. epidermis 2); Escherichia coli 830 (E. coli 830); Escherichia coli 986 (E. coli 986); Klebsiella pneumoniae 822 (K. pneumoniae 822).

\subsubsection{Propagation and Maintenance of Microorganisms}

The studied microorganisms were streaked on the nutrient agar slants and then incubated overnight at $\left(37 \pm 1{ }^{\circ} \mathrm{C}\right)$. The cultures were kept under refrigerated conditions and were sub-cultured every fifteen days.

\subsubsection{In Vitro Testing}

Empty sterilized discs were impregnated with $5 \mu 1$ of oil diluted with DMSO to obtain different concentrations $(5 \%, 10 \%, 20 \%, 40 \%, 60 \%, 80 \%$ and $100 \%)$. DMSO was used as negative control. The inoculated plates were incubated at $37^{\circ} \mathrm{C}$ for 24 or 48 hours for bacterial and fungal assessment, respectively. Antibacterial activity was evaluated by measuring the zone of inhibition in millimeters after the incubation period. All experiments were done in triplicate and the results are presented as mean \pm standard deviation of three independent experiments.

\subsubsection{In Vitro Antibacterial Activity}

Antibacterial activity was determined by the disk diffusion method (Bauer et al., 1996). A positive control was done using the following antibiotics: methicillin $(5 \mu \mathrm{g} / \mathrm{disc})$; penicillin $(10 \mu \mathrm{g} / \mathrm{disc})$; amoxicillin/clavulanic acid 
(augmentim) (30 $\mu \mathrm{g} / \mathrm{disc})$; vancomycin $(5 \mu \mathrm{g} / \mathrm{disc})$ in Gram positive strains and ciprofloxacin $(5 \mu \mathrm{g} / \mathrm{disc})$, nitrofurantoin $(300 \mu \mathrm{g} / \mathrm{disc})$, ceftazidime $(30 \mu \mathrm{g} / \mathrm{disc})$; gentamicin $(10 \mu \mathrm{g} / \mathrm{disc})$ in Gram negative strains and a negative control was performed with DMSO for all tested strains. The antibacterial activity of all the tested antibiotics was interpreted according to the CLSI guidelines (2012).

\subsubsection{In Vitro Antifungal Activity}

Antifungal activity was also evaluated by the disk diffusion method in accordance to CLSI guidelines M44-A2. Candida spp. were tested in agar Miller Hinton (DIFCO) supplemented with $2 \%$ of glucose and $0.5 \mathrm{~g} / \mathrm{ml}$ of methylene blue. Yeast suspension was adjusted to a final concentration between 1 and $5 \times 10^{6}$ cells $/ \mathrm{ml}$ and incubated at $35^{\circ} \mathrm{C}$ during 48 hours. The antifungal fluconazole, at a concentration of $5 \mu \mathrm{g} / \mathrm{disc}$, was the positive control to Candida spp. Results were interpreted according to CLSI guidelines (2012).

\subsection{Statistical Analysis}

Data are reported as mean \pm standard deviation of nine measurements. Statistical analysis was performed using the statistical software package SPSS v 20.0 (SPSS for Windows; SPSS Inc., Chicago, IL). Mean comparison was made through an independent sample t-test. Levene's test was utilized to assess the equality of variances. One-way ANOVA was used to compare three or more groups, and post-hoc Dunnett's test was performed for simultaneous paired comparisons. $P$ values less than 0.05 (95\% confidence level) are reported as "statistically significant".

\section{Results and Discussion}

The results of the chromatographic analysis of the $C$. citratus EO presented in Table 1 reveal that the chemical compositon of $C$. Citratus EO obtained from plants grown in Angola is similar to that of plants from other provenances (Sessou et al., 2012; Tajidin et al., 2012; Masamba et al., 2003). Accordingly, the major constituents are $\alpha$-citral (40.55\%), $\beta$-citral (28.26\%), myrcene (10.50\%) and geraniol (3.37\%). The volatile fraction of C. citratus EO revealed the presence of 10 different compounds accounting for $83.86 \%$ of total peak area.

Table 1. Angolan C. citratus EO main components as revealed by GC-MS

\begin{tabular}{lll}
\hline Components & $\mathrm{RI}^{\mathrm{a}}$ & Peak area (\%) \\
\hline 6-methyl-5-hepten-2-one & 8.725 & 0.97 \\
Myrcene & 8.875 & 10.50 \\
$\alpha$-(Z)-Ocymene & 10.533 & 0.22 \\
$\beta$-(E)-Ocymene & 10.917 & 0.27 \\
Linalool & 12.883 & 0.50 \\
Citronelal & 14.250 & 0.11 \\
$\beta$-citral & 18.025 & 28.26 \\
Geraniol & 18.458 & 2.37 \\
$\alpha$-citral & 19.142 & 40.55 \\
Linalool isobutyrate & 22.967 & 0.11 \\
\hline
\end{tabular}

${ }^{\mathrm{a}}$ Retention index relative to $\mathrm{n}$-alkanes.

The preservation of food generally requires the use of various compounds to perform a range of functions namely antioxidants, antibacterial and antifungals. The ideal would be to find a single biopreservative that could perform all these functions simultaneously. In order to assess the antioxidant potential of the $C$. citratus EO, its free radical scavenging activity by the DPPH assay was measured (Figure 1). 


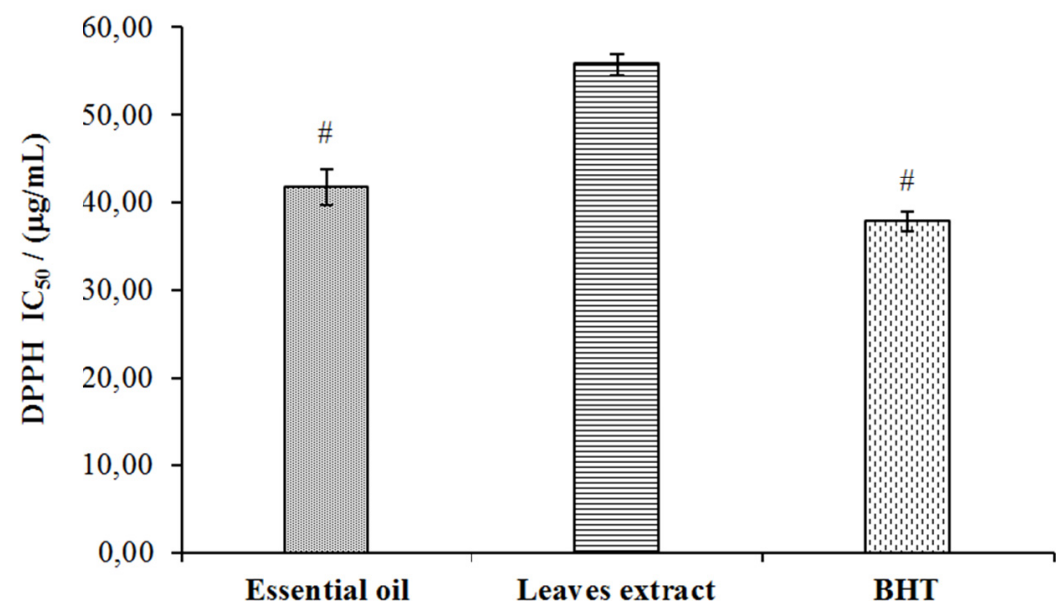

Figure 1. Free radical scavenging activities of the $\mathrm{EO}$ and methanolic extract obtained from the leaves of Angolan C. citratus versus BHT. "Statistically identical (95\% significance)

Our results showed that no statistical significant differences exist between the free radical scavenging activities of the EO and butylated hydroxytoluene (BHT). The EO was able to reduce the stable free radical 2,2'-diphenyl-1-picrylhydrazyl to diphenylpicrylhydrazine with an $\mathrm{IC}_{50}$ of $41.7 \mu \mathrm{g} / \mathrm{ml}$, a value similar to that of the synthetic antioxidant $(37.7 \mu \mathrm{g} / \mathrm{ml})$. The dried leaves methanolic extract was found to be less efficient in radical scavenging with an $\mathrm{IC}_{50}$ value of $55.7 \mu \mathrm{g} / \mathrm{ml}$. The bioactive compounds found in vegetables do not all have the same antioxidant activity, in fact the phenolic compounds are known to have higher antioxidant activity than monoterpenoids (Gharib \& Silva, 2013). The total phenolics contents found in the leaves were 578.32 \pm 0.60 $\mathrm{mg} / \mathrm{kg}$, nonetheless it is well known fact that for a complex extract, as the one in question, it is also necessary to take into account the synergistic or antagonistic effects among the various compounds present, which makes the antioxidant activity not only dependent of the concentration of each compound but also of the interaction between different compounds, antioxidants or not (Sanjust et al., 2008).Thus, an increase in the level of a compound does not mean a proportional increase of antioxidant activity of the matrix. We attribute the high antioxidant activity manifested by the EO to the synergic action of the monoterpenoid compounds such as $\alpha$-citral, $\beta$-citral, and myrcene (Ruberto \& Baratta, 2000). The chromatographic analysis (Table 1) reveals that these are abundant in the EO.

C. citratus $\mathrm{EO}$ was found to have greater antioxidant activity than methanolic extracts obtained from the leaves and similar to that exhibited by the synthetic antioxidant BHT. In this respect, however, the oil possesses an important advantage over BHT: due to their natural origin, the antioxidants obtained from plants do not induce the negative side effects provoked by synthetic ones, such as BHT, which has proved to cause hemorrhaging (Ndhlala et al., 2010).

The antibacterial activity of the EO of the Angolan C. citratus is depicted in Figures 2 and 3. 

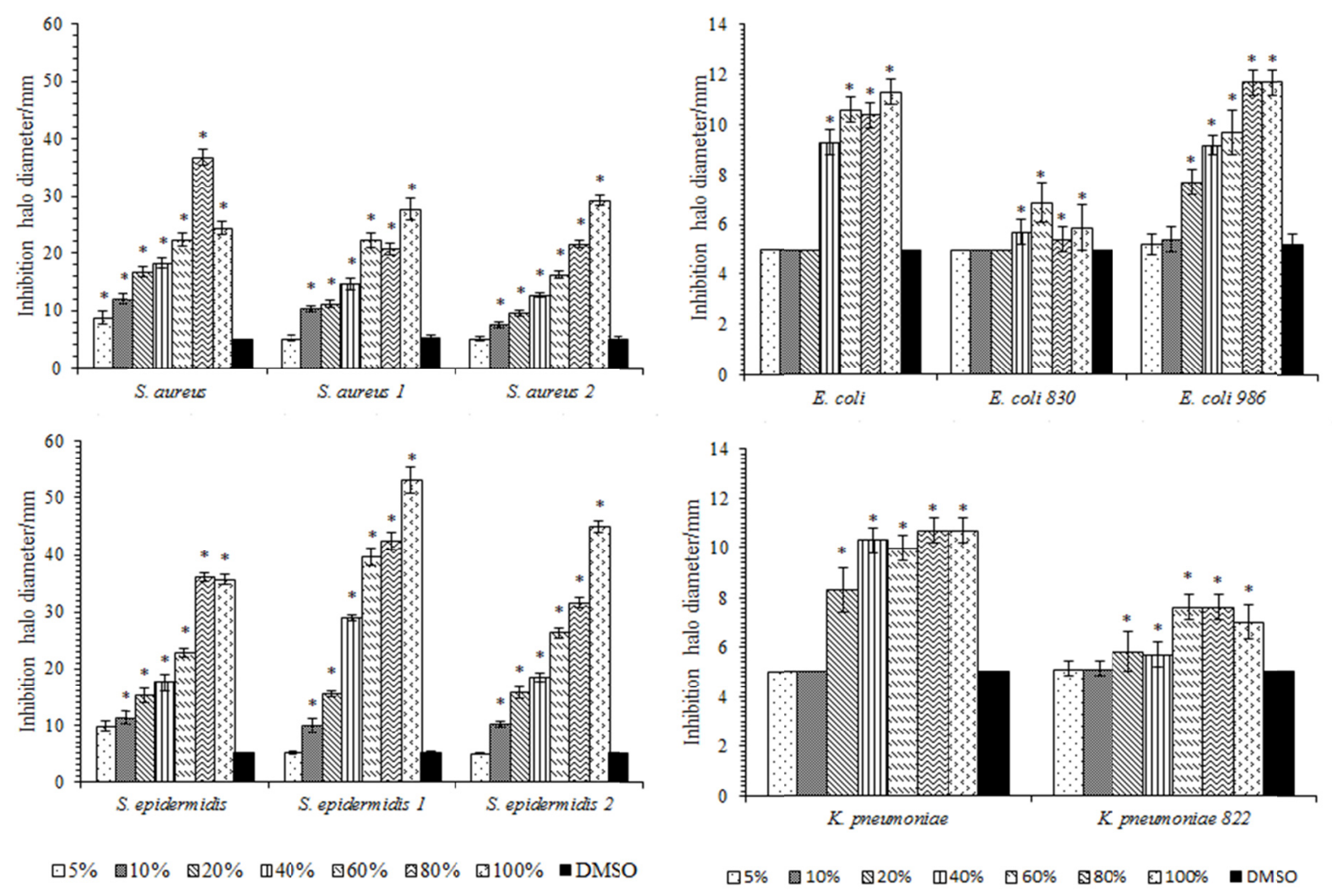

Figure 2. Antibacterial activity of different EO concentrations of $C$. citratus against Gram positive ATCC and multidrug resistant strains. *Statistically different (95\% significance) relatively to negative control DMSO

Figure 3. Antibacterial activity of different EO concentrations of C. citratus against Gram negative ATCC and multidrug resistant strains. *Statistically different (95\% significance) relatively to negative control DMSO

It can be seen that hospital isolated $S$. aureus 1 and $S$. aureus 2 were sensitive to $C$. citratus $\mathrm{EO}$ at concentrations equal or superior to $60 \%$ while $S$. aureus ATCC 25923 growth was inhibited at even lower concentrations $(\geq$ 20\%). S. epidermidis ATCC 12228 and the hospital isolated strains S. epidermidis 1 and S. epidermidis 2 had a similar pattern of sensitivity at EO concentrations equal or above $20 \%$. These results are, in our view, relevant since they demonstrate the potential of the Angolan $C$ citratus EO as an antibacterial agent even against multidrug resistant strains. In order to better understand the effectiveness of the EO, the antibacterial activity of antibiotics in use against the strains studied was also evaluated. The results are summarized in Table 2.

Table 2. Antibiotic sensitivity pattern of multidrug resistant hospital isolated strains and their respective ATCC control strains

\begin{tabular}{|c|c|c|c|c|c|}
\hline Bacteria $($ Gram +$)$ & MET & $\mathrm{P}$ & AMC/AUG & VA & $\begin{array}{l}\text { C. citratus EO concentration } \\
(\%)\end{array}$ \\
\hline${ }^{*} S$. aureus & $\mathrm{S}$ & $\mathrm{S}$ & $\mathrm{S}$ & - & $\mathrm{S} \geq 20$ \\
\hline S. aureus $_{1}$ & $\mathrm{R}$ & $\mathrm{R}$ & $\mathrm{R}$ & - & $\mathrm{S} \geq 40$ \\
\hline S. aureus ${ }_{2}$ & $\mathrm{R}$ & $\mathrm{R}$ & $\mathrm{R}$ & - & $S \geq 60$ \\
\hline${ }^{*}$ S. epidermidis & $\mathrm{S}$ & $\mathrm{R}$ & S & S & $S \geq 20$ \\
\hline S. epidermidis ${ }_{1}$ & $\mathrm{R}$ & $\mathrm{R}$ & $\mathrm{R}$ & $\mathrm{R}$ & $\mathrm{S} \geq 20$ \\
\hline S. epidermidis ${ }_{2}$ & I & $\mathrm{R}$ & $\mathrm{S}$ & $\mathrm{R}$ & $S \geq 20$ \\
\hline
\end{tabular}

Sensitivity values: R-Resistant; $\quad$ I-Intermediate; $\quad$ S-Sensitive. $\quad$ MET-Methicillin; $\quad$ P-Penicillin; AMC/AUG-Amoxicillin/Clavulamic acid; VA-Vancomycin (from CLSI guidelines). 
Both hospitalar isolated strains of $S$. aureus presented an analogous pattern of resistance to methicillin, penicillin and amoxicillin-clavulamic acid, consistent with methicillin resistant profile. S. aureus (ATCC 25923) presented the expected sensitivity relatively to the tested antibiotics that usually have inhibitory effect on Gram positive bacteria (Table 2). S. epidermidis 1 was resistant to methicillin, penicillin and amoxicillin-clavulamic acid and vancomycin consistent also with the methicillin resistant profile. S. epidermidis 2 was sensitive to amoxicillin-clavulamic acid and resistant to penicillin, methicillin and vancomycin. By comparison, $S$. epidermidis ATCC 12228 was sensitive to all antibiotics tested for Gram positive bacteria.

Gram negative E. coli 830, E. coli 986 and K. pneumoniae 822 presented an intermediate resistance pattern, with growth inhibition at $C$. citratus EO concentrations equal or superior to $40 \%$ (Figure 3). In the case of $E$. coli 986 and $K$. pneumoniae the inhibition effect of the EO started at inferior concentrations $(\geq 20 \%)$.

The results thereby suggest that the oil is more effective on Gram positive bacteria. The higher resistance manifested by the Gram negative bacteria may be associated to the constitution of its outer membrane which acts as a relatively impermeable barrier (Nikaido, 2003). Gram negative bacteria are inherently resistant to hydrophobic antibiotics, as their outer membrane limits the entry of these antibiotics into the cell (Poole, 2002). Thus we can hypothesize that the $C$. citratus EO is less effective against Gram negative bacteria due to the same reason (Saha et al., 2008).

In the last decades, fungi have emerged as major causes of human disease, with invasive candidiasis (IC) as a leading cause of mycosis-associated mortality in developed countries (Pfaller \& Diekema, 2007). Candida albicans (C. albicans) is the most frequent species isolated, but other Candida are of special concern, due to abnormal virulence and reduced susceptibility to antifungal agents. C. parapsilosis and C. tropicalis are the most prevalent NCAC species with a crescent number of infections (Trofa et al., 2008; Kothavade et al., 2010). The $C$. citratus EO showed effectiveness in inhibiting the growth of all yeast strains studied as shown in Figure 4. This Candida also revealed sensitivity to fluconazol. No effect on yeast growth was detected when exposed to DMSO.

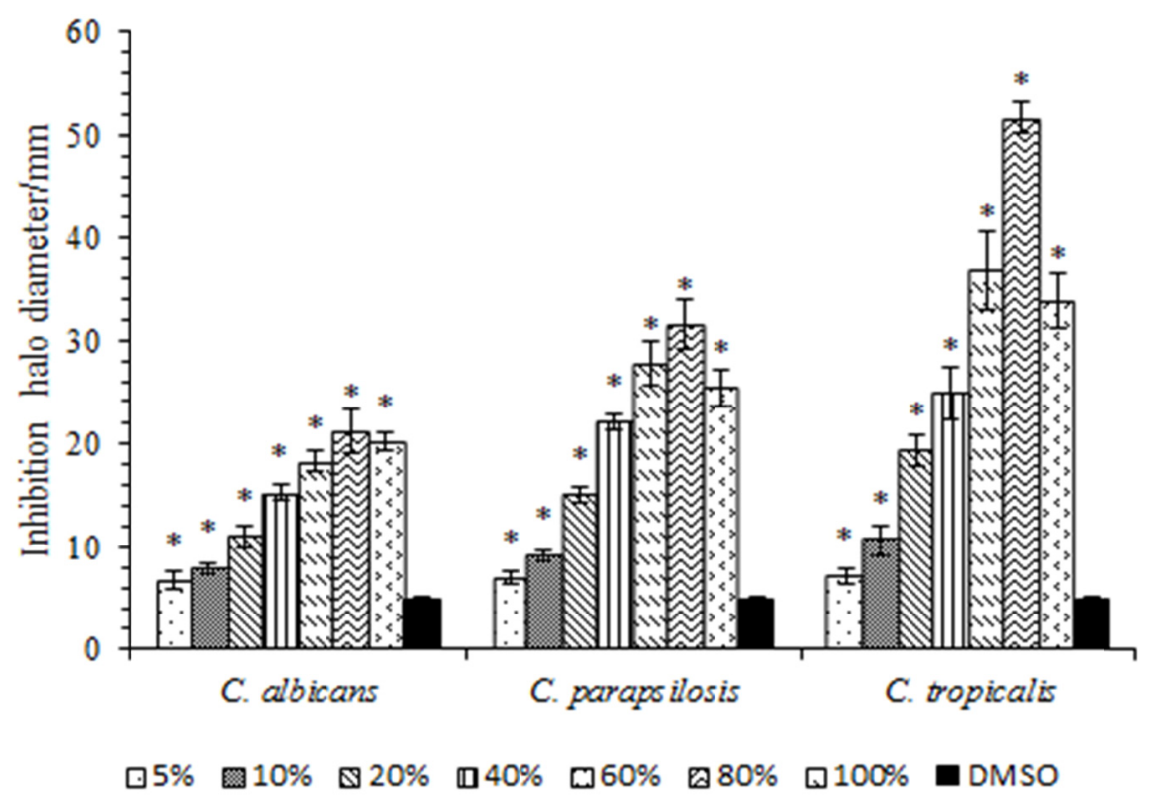

Figure 4. Antifungal activity of different $C$. citratus EO concentrations against Candida spp. * statistically different (95\% significance) from negative control DMSO

Data on C. albicans is in accordance with other studies (Irkin et al., 2009; Tyagi et al., 2010) but, to the best of our knowledge, this is the first reported data on EO antifungal activity on the NCAC. The fact that EO has proved effective against NCAC at all concentrations tested is the more relevant as recent epidemiologic studies report that NCAC are currently estimated to be responsible for approximately $60 \%$ of fungaemia (Silva et al., 2009). These results put in evidence the antifungal activity of $C$. citratus EO, which should be considered in further investigations namely in order to assess the sensitivity of other NCAC. 


\section{Conclusions}

The Angolan C. citratus EO was found to have greater antioxidant activity than methanolic extracts obtained from the leaves and similar to that exhibited by the synthetic antioxidant BHT. The EO exhibited high antibacterial and anti-yeast properties including against multidrug resistant strains of $S$. aureus, S. epidermidis, $E$. coli, K. pneumonia and NCAC spp C. parapsilosis and C. tropicalis. Taking into account the results of this study and the already reported antimicrobial activity of the $C$. citratus EO against many other pathogenic or spoilage microorganisms, it can be concluded that it meets several features that make it a good candidate for the biopreservation of food.

\section{References}

Bauer, A. W., Kirby, W. M., Sherris, J. C., \& Turck, M. (1996). Antibiotic susceptibility testing by standardized single disc method. American Journal Clinical Pathology, 44, 493-496. Retrieved from www.ncbi.nlm.nih.gov/pubmed/5325707

Bidinotto, L. T., Costa, C. A., Costa, M., Rodrigues, M. A., \& Barbisan, L. F. (2012). Modifying effects of lemongrass essential oil on specific tissue response to the carcinogen N-methyl-N-nitrosurea in female BALB/c mice. Journal Medicinal Food, 15, 161-168. http://dx.doi.org/10.1089/jmf.2011.0005

Brand-Williams, W., Cuvelier, M. E., \& Berset, C. (1995). Use of a free radical method to evaluate antioxidant activity. Food Science Technology, 28(1), 25-30. http://dx.doi.org/10.1016/S0023-6438(95)80008-5

Clinical and Laboratory Standards Institute. (2012). Method for antifungal disk diffusion susceptibility testing of yeasts: approved guideline M44-A2. CLSI, Wayne, PA, USA. Retrieved from www.clsi.org

Costa, C. A., Bidinotto, L. T., Takahira, R. K., Salvadori, D. M., Barbisan, L. F., \& Costa, M. (2011). Cholesterol reduction and lack of genotoxic or toxic effects in mice after repeated 21-day oral intake of lemongrass (Cymbopogon citratus) essential oil. Food Chemistry Toxicology, 49, 2268-2272. http://dx.doi.org/10.1016/j.fct.2011.06.025

Easa, S. M. H. (2010). Microorganisms found in fast and traditional fast food. Journal American Science, 6(10), 515-531. Retrieved www.jofamericanscience.org/journals/am-sci/am0610/61_3463am0610_515_531.pdf

European Pharmacopoeia (6th ed.). (2007). Council of Europe, Retrieved from http://www.edqm.eu/en/european-pharmacopoeia-publications-1401.html

Falcão, M. A., Fianco, A. L. B., Lucas, A. M., Pereira, M. A. A., Torres, F. C., Vargas, R. M. F., \& Cassel, E. (2012). Determination of antibacterial activity of vacuum distillation fractions of lemongrass essential oil. Phytochemistry, 11. http://dx.doi.org/10.1007/s11101-012-9255-3

Fry, D. E. (2013). The continued challenge of Staphylococcus aureus in the surgical patient. American Surgery, 79, 1-10. http://dx.doi.org/10.1089/sur.2011.068

Gbenou, J. D., Ahounou, J. F., Akakpo, H. B., Laleye, A, Yayi, E., Gbaguidi, F., ... Kotchoni, S. O. (2013). Phytochemical composition of Cymbopogon citratus and Eucalyptus citriodora essential oils and their anti-inflammatory and analgesic properties on Wistar rats. Molecular Biology Reports, 40, 1127-1134. http://dx.doi.org/10.1007/s11033-012-2155-1

Gharib, F., \& Silva, J. (2013). Composition, total phenolic content and antioxidant activity of the essential oil of four Lamiaceae herbs. Medicinal and Aromatic Plant Science and Biotechnology, 7(1) 19-27. Retrived from http://www.globalsciencebooks.info/Journals/MAPSB.html

Hyldgaard, M., Mygind, T., \& Meyer, R. L. (2012). Essential oils in food preservation: mode of action, synergies, and interactions with food matrix components. Frontiers Microbiology, 3(12), 1-24. http://dx.doi.org/10.3389/fmicb.2012.00012

Irkin, R., \& Korukluoglu, M. (2009). Effectiveness of Cymbopogon citratus L. essential oil to inhibit the growth of some filamentous fungi and yeasts. Journal Medicinal Food, 12, 193-197. http://dx.doi.org/10.1089/jmf.2008.0108

Jang, H. D., Chang, K. S., Huang, Y. S., Hsu, C. L., Lee, S. H., \& Su, M. S. (2007). Principal phenolic phytochemicals and antioxidant activities of three Chinese medicinal plants. Food Chemistry, 103(3), 749-756. http://dx.doi.org/10.1016/j.foodchem.2006.09.026 
Kahl, R., \& Kappus, H. (1993). Toxicology of the synthetic antioxidants BHA and BHT in comparison with the natural antioxidant vitamin E. Z Lebensm Unters Forrsch, 196(4), 329-338. http://dx.doi.org/10.1007/BF01197931

Kim, S. H., Wei, C. I., Tzou, Y. M., \& An, H. (2005). Multidrug-resistant Klebsiella pneumoniae isolated from farm environments and retail products in Oklahoma. Journal Food Protection, 68(10), 2022-2029. Retrieved from www.ncbi.nlm.nih.gov/pubmed/16245702

Kothavade, R. J., Kura, M. M., Valand, A. G., \& Panthaki, M. H. (2010). Candida tropicalis: its prevalence, pathogenicity and increasing resistance to fluconazole. Journal Medical Microbiology, 59, 873-880. http://dx.doi.org/10.1099/jmm.0.013227-0

Lang, G., \& Buchbauer, G. (2012). A review on recent research results (2008-2010) on essential oils as antimicrobials and antifungals. A review. Flavour Fragance Journal, 27(1), 13-39. http://dx.doi.org/10.1002/ffj.2082

Mahanta, J. J., Chutia, M., Bordoloi, M., Pathak, M. G., Adhikary, R. K., \& Sarma, T. C. (2007). Cymbopogon citratus L. essential oil as a potential antifungal agent against key weed moulds of Pleurotus spp. spawns. Flavour Fragrance Journal, 22, 525-530. http://dx.doi.org/10.1002/ffj.1835

Masamba, W. R. L., Kamanula, J. F. M., Henry, E. M. T., \& Nyirenda, G. K. C. (2003). Extraction and analysis of lemongrass (Cymgopogon citratus) oil: As essential oil with potential to control the Larger Grain Borer (Prostephanus truncatus) in stored products in Malawi. Malawi Journal Agriculture Science, 2(1), 56-64. Retrieved from www.cabdirect.org/abstracts/20083325277.html

McAdam, P. R., Templeton, K. E., Edwards, G. F., Holden, M. T. G., Feil, E. J., Aanensen, D. M., ... Fitzgerald, J. R. (2012). Molecular tracing of the emergence, adaptation, and transmission of hospital-associated methicillin-resistant Staphylococcus aureus. Proceedings National Academy Sciences, 109, 9107-9112. http://dx.doi.org/10.1073/pnas.1202869109

Montagna, M. T., Erroi, R., Sanapo, S., Caggiano, G., Bagordo, F., \& De Donno, A. (1998). Food products and fungal contamination. Note I. Preliminary investigation in commercial yoghurt. Journal Preventive Medicine Hygiene, 39, 68-70. Retrieved from www.jpmh.org/issues/19983915.pdf

Muñoz, P., Singh, N., \& Bouza, E. (2006). Treatment of solid organ transplant patients with invasive fungal infections: should a combination of antifungal drugs be used? Current Opinion. Infectious Disease, 19, 365-370. http://dx.doi.org/10.1097/01.qco.0000235164.70678.97

Naik, M. I., Fomda, B. A., Jaykumar, E., \& Bhat, J. A. (2010). Antibacterial activity of lemongrass (Cymbopogon citratus) oil against some selected pathogenic bacteria's. Asian Pacific Journal of Tropical Medicine, 3(8), 535-538. http://dx.doi.org/10.1016/S1995-7645(10)60129-0

Ndhlala, A. R., Moyo, M., \& Van Staden, J. (2010). Natural antioxidants: fascinating or mythical biomolecules? Molecules, 15(10):6905-6930. http://dx.doi.org/10.3390/molecules15106905

Nikaido, H. (2003). Molecular basis of bacterial outer membrane permeability revisited. Microbiology Molecular Biology Reviews, 67, 593-656. http://dx.doi.org/10.1128/MMBR.67.4.593-656.2003

Pfaller, M. A., \& Diekema, D. J. (2007). Epidemiology of Invasive Candidiasis: a persistent public health problem. Clinical Microbiology Reviews, 20, 133-163. http://dx.doi.org/10.1128/CMR.00029-06

Poole, K. (2002). Outer membranes and efflux: the path to multidrug resistance in gram-negative bacteria. Current Pharmaceutical Biotechnology, 3, 77-98. http://dx.doi.org/10.2174/1389201023378454

Rodloff, A. C., Koch, D., \& Schaumann, R. (2011). Epidemiology and antifungal resistance in invasive candidiasis. European Journal Medical Research, 16, 187-195. http://dx.doi.org/10.1186/2047-783X-16-4-187

Ruberto, G., \& Baratta, M. T. (2000). Antioxidant activity of selected essential oils components in two lipid model systems. Food Chemistry, 69, 167-174. http://dx.doi.org/10.1016/S0308-8146(99)00247-2

Sabota, J. M., Hoppes, W. L., Ziegler, J. R., DuPont, H., Mathewson, J., \& Rutecki, G. W. (1998). A new variant of food poisoning: enteroinvasive Klebsiella pneumoniae and Escherichia coli sepsis from a contaminated $\begin{array}{llll}\text { hamburger. } & \text { American }\end{array}$ http://dx.doi.org/10.1111/j.1572-0241.1998.118_c.x

Saeio, K., Chaiyana, W., \& Okonogi, S. (2011). Antityrosinase and antioxidant activities of essential oils of edible Thai plants. Drug Discoveries Therapeutics, 5, 144-149. http://dx.doi.org/10.5582/ddt.2011.v5.3.144 
Saha, S., Savage, P. B., \& Bal, M. (2008). Enhancement of the efficacy of erythromycin in multiple antibiotic-resistant gram-negative bacterial pathogens. Journal Applied. Microbiology, 105, 822-828. http://dx.doi.org/10.1111/j.1365-2672.2008.03820.x

Sanjust, E., \& Mocci, G. (2008). Mediterranean shrubs as potential antioxidant sources. Natural Product Research, 22(8), 689-708. http://dx.doi.org/10.1080/14786410801997125

Schelin, J., Wallin-Carlquist, N., Cohn, M. T., Lindgvist, R., Barker, G. C., \& Radstrom, P. (2011). The formation of Staphylococcus aureus enterotoxin in food environments and advances in risk assessment. Virulence, 2(6), 580-592. http://dx.doi.org/10.4161/viru.2.6.18122

Sessou, P., Farougou, S., Kaneho, S., Djenontin, S., Alitonou, G. A., Azokpota, P., Youssao, I., \& Sohounhloué, D (2012). Bioefficacy of Cymbopogon citratus essential oil against foodborne pathogens in culture medium and in traditional cheese wagashi produced in Benin. International Research Journal Microbiology, 3(12), 406-415. Retrieved from interesjournals.org/irjm/pdf/2012/december/sessou\%20et\%20al.pdf

Silva, S., Negri, M., Henriques, M., Oliveira, R., Williams, D. W., \& Azeredo, J. (2012). Candida glabrata, Candida parapsilosis and Candida tropicalis: biology, epidemiology, pathogenicity and antifungal resistance. FEMS Microbiology Letters, 36, 288-305. http://dx.doi.org/10.1111/j.1574-6976.2011.00278.x

Tajadin, N. E., Ahmad, S. H., Rosenani, A. B., Azimah, H., \& Munirah, M. (2012). Chemical composition and citral content in lemongrass (Cymbopogon citratus) essential oil at three maturity stages. African Journal Biotechnology, 11(11), 2685-2693. http://dx.doi.org/10.5897/AJB11.2939

Trofa, D., Gacser, A. \& Nosanchuk, J. D. (2008). Candida parapsilosis, an emerging fungal pathogen. Clinical Microbiology Reviews, 21, 606-625. http://dx.doi.org/10.1128/CMR.00013-08

Tyagi, A. K., \& Malik, A. (2010). Liquid and vapour-phase antifungal activities of selected essential oils against Candida albicans: microscopic observations and chemical characterization of Cymbopogon citratus. BMC Complementary Alternative Medicine, 10, 10-65. http://dx.doi.org/10.1186/1472-6882-10-65

Widerström, M., McCullough, C. A., Coombs, G. W., Monsen, T., \& Christiansen, K. J. (2012). A Multidrug-Resistant Staphylococcus epidermidis clone (ST2) is an ongoing cause of hospital-acquired infection in a western Australian hospital. Journal Clinical Microbiology, 50, 2147-2215. http://dx.doi.org/10.1128/JCM.06456-11

\section{Copyrights}

Copyright for this article is retained by the author(s), with first publication rights granted to the journal.

This is an open-access article distributed under the terms and conditions of the Creative Commons Attribution license (http://creativecommons.org/licenses/by/3.0/). 